\title{
Chemotherapy versus chemoradiotherapy for FIGO stages IB1 and IIA1 cervical squamous cancer patients with lymphovascular space invasion: a retrospective study
}

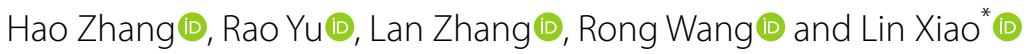

\begin{abstract}
Purpose: To evaluate the impact of different adjuvant therapy on IB1 and IIA1 stage cervical squamous cell cancer patients with lymphovascular space invasion. It also aimed to analyze the relationship between lymphovascular space invasion and other clinical pathological characteristics on IB1 and IIA1 stage cervical squamous cell cancer patients.

Methods: This retrospective observational study collected data of FIGO stages IB1 and IIA1 squamous cervical cancer patients at the First Affiliated Hospital of Chongqing Medical University between 2014 and 2018. A correlation analysis between lymphovascular space invasion and other clinical or pathological factors was conducted. Prognosis analysis of patients with lymphovascular space invasion were performed to assess associations between clinical-pathological characteristics and survival.

Results: A total of 357 women were identified including 110 (30.8\%) with lymphovascular space invasion, 247 (69.2\%) without lymphovascular space invasion. Both middle $1 / 3$ cervical stromal invasion $(p=0.000)$ and deep 1/3 cervical stromal invasion $(p=0.000)$ were independently associated with lymphovascular space invasion. Among lymphovascular space involved women, tumor differentiation $(P=0.001)$ and postoperative therapy $(P=0.036)$ had a significant influence on disease recurrence. Multivariate analysis showed that lymph node metastasis $(P=0.017)$, poorer tumor differentiation $(P=0.036)$ and postoperative chemotherapy alone $(P=0.021)$ can increase the risk of tumor relapse.
\end{abstract}

Conclusion: Our study suggested that the presence of deep stromal invasion independently increases the risk of lymphovascular space invasion. Compared with chemotherapy, chemoradiotherapy seems to improve progressionfree survival in squamous cervical cancer patients with lymphovascular space invasion.

Keywords: Uterine cervical neoplasms, Risk factor, Chemoradiotherapy, Chemotherapy, Adjuvant, Progression-free survival, Survival analysis

*Correspondence: xiaolin@hospital.cqmu.edu.cn

Department of Gynecology, The First Affiliated Hospital of Chongqing

Medical University, Chongqing 400016, China

\section{Introduction}

Cervical cancer, being the fourth most frequent malignant tumor among women, is also one of the leading causes of female death. In 2020, it was estimated that there were 604,000 new cases of cervical cancer and 342,000 deaths worldwide [1]. Approximately $80 \%$ of all cervical cancer are squamous cell cancer, while 
adenocarcinoma and other pathological type makes up the rest. With the popularization of the screening test, more and more patients are diagnosed with cervical cancer in an early stage. Surgery is the preferred modality for the treatment of early invasive cervical cancer (FIGO stage 2009 IB1, IIA1), which usually consists of a type $C$ radical hysterectomy with pelvic lymphadenectomy [2]. Following radical hysterectomy, postoperative treatment is indicated for patients with adverse pathologic factors.

Among various pathologic factors, lymph node metastasis, parametrial involvement and positive surgical margins are considered high-risk factors for the poor prognosis of cervical cancer, while lymphovascular space invasion (LVSI), deep stromal invasion (DSI) and tumor diameter greater than $4 \mathrm{~cm}$ are considered as intermediate risk factors [2, 3]. Lymphovascular space invasion is the presence of cancer cell clusters inside endotheliumlined channels of uterine specimens [4]. LVSI is considered to be an important risk factor which portends poor prognosis in patients with low-risk endometrial cancer, and it is also found to be associated with lymph node metastasis [4-10]. However, there's only limited data on the prognosis of cervical cancer patients with LVSI, with very heterogeneous results. It is generally agreed that LVSI is related to poor prognosis of cervical cancer, while there is still controversy on whether it is an independent prognostic factor and its association to other pathological risk factors.

Generally, for patients with high-risk individuals, postoperative radiotherapy plus concurrent platinum-based chemotherapy is recommended. However, for patients with intermediate risk factors, postoperative therapeutic regimen still remains controversial.

There are guidelines recommended that pelvic radiotherapy with (or without) concurrent platinum-containing chemotherapy should be offered to patients with combination of any two or three of the intermediate risk factors. This recommendation is based on a prospective randomized study (GOG \#92), while in 2006 the followup of the same study revealed that even if adjuvant radiotherapy significantly reduces the risk of recurrence and prolongs progression-free survival (PFS) in women with Stage IB cervical cancer, the overall survival (OS) did not change significantly (p 0.074) $[11,12]$. Therefore, some studies have attempted to add chemotherapy to adjuvant radiotherapy, and found that compared with radiotherapy alone, chemoradiotherapy might be more effective as an adjuvant therapy for intermediate-risk early cervical cancer [13-17]. On the contrary, a randomized phase III trial revealed that chemoradiotherapy is not superior to radiotherapy alone for early stage cervical cancer patients with intermediate-risk factor [18].
The present study was aimed to evaluate the impact of different adjuvant therapy on IB1 and IIA1 stage cervical squamous cell cancer patients with LVSI as well as to analyze the relationship between LVSI and other clinical pathological characteristics.

\section{Materials and methods}

Postoperative patients who had early-stage cervical cancer at the First Affiliated Hospital of Chongqing Medical University in recent years were retrospectively analyzed. Medical records were obtained with informed consent of all patients. The inclusion criteria were: (1) diagnosed with cervical cancer at the First Affiliated Hospital of Chongqing Medical University from February 1, 2015 to December 31, 2018; (2) FIGO stage (2009) IB1 or IIA1; (3) with definite histological diagnosis of squamous cell cancer; (4) has received a radical hysterectomy with pelvic lymphadenectomy; (5) with or without lymphovascular space invasion and other risk factors. Exclusion criteria including: (1) has received surgery or chemotherapy or radiotherapy for cervical cancer at other hospital before the consultation at the First Affiliated Hospital of Chongqing Medical University;(2) has received neo-adjuvant therapy; (3) with any component of adenocarcinoma, neuroendocrine carcinoma or other differentiation within the tumor; (4) accompanied by any other kind of malignancy; (5) absence of follow-up data.

The baseline information of included patients was retrieved from patient files, including age, BMI, FIGO stage, approach of surgery, value of squamous cell carcinoma antigen (SCC, $\mathrm{ng} / \mathrm{ml}$ ), clinical tumor size. Each patient has received a pathological examination after the surgery, data as follows were collected: pathological type, tumor differentiation grade, lymphovascular space invasion, deep stromal invasion, lymph nodes involvement, parametrial involvement, surgical margin involvement and expression of P16. All the surgeries were performed by qualified and experienced surgeon. The determination of postoperative treatment was based on practitioners' assessment of the condition as well as patient's intention to treatment. For patients received chemotherapy, the cisplatin-based plus paclitaxel regimen was given every 3 weeks, consisting of paclitaxel $135 \mathrm{mg} / \mathrm{m}^{2}$ and cisplatin $60 \mathrm{mg} / \mathrm{m}^{2}$ for $2-6$ cycles. For patients received radiotherapy, intensity-modulated pelvic radiotherapy (IMRT) with a dose of 50Gy in 25-28 fractions was prescribed. In cases with positive lymph node, regional radiation dose can be increased upto 60Gy. Prognosis information such as recurrence, metastasis, and death were obtained from medical record or telephone interview. All patients were followed up until December, 2020. The primary endpoints of the present study were overall survival (OS) and progression-free survival (PFS). OS was defined as 
the time from surgery to death of any reason or the most recent follow-up, and PFS was define as the time from surgery to recurrence or metastasis [19].

All patients were enrolled in a correlation analysis between LVSI and other clinical or pathological factors. Patients were grouped according to the presence of LVSI. Chi-square test and t-test was used to compare demographic and clinical-pathological characteristics between LVSI-positive (LVSI+) and LVSI-negative (LVSI-) individuals. Binary Logistic regression was used for multivariate analysis. Patients with LVSI+ were grouped according to different type of adjuvant therapy (observation, chemotherapy alone (CT), radiotherapy alone (RT), chemoradiotherapy (CRT)). Patients with observation and radiotherapy alone were not included in the comparison because of limited data (6 patients of observation and none of radiotherapy alone). Clinical and pathological characteristics of included individuals were compared using chi-square test or Fisher exact test for frequencies and student $\mathrm{t}$-test for continuous variables. The prognosis information such as PFS and OS was calculated by Kaplan-Meier method, and Log-rank statistic were used to analyze differences between groups. Cox proportional hazard model for multivariate analysis were performed to evaluate the relationship between other clinical or pathological factors and prognosis. Characteristics included into multivariate analysis were chosen before data collection to be clinically significant. Differences were considered as statistically significant if $\mathrm{P}<0.05$. All statistical analyses were performed by SPSS software, standard version 25.0 (IBM Corp., Armonk, NY, USA).

\section{Results}

A total of 357 women were enrolled in our study, 247 (69.2\%) patients were LVSI-, 110(30.8\%) patients were LVSI+ (Table 1). Between LVSI+ and LVSI- group, a significant difference was found in BMI $(p=0.030)$, SCC value $\geq 1.5 \mathrm{ng} / \mathrm{mg}(p=0.000)$, tumor size $\geq 2 \mathrm{~cm}$ $(p=0.002)$, FIGO stage $(p=0.000)$, lymph node involvement $(p=0.000)$ and depth of stromal invasion $(p=0.000)$. While difference in age, surgical approach and tumor differentiation were not significant. None of the 357 women presented parametrial invasion or positive surgical margin. Furthermore, binary Logistic regression indicated that among analyzed characteristics, depth of stromal invasion was the single independent risk factor of LVSI (Table 2). Both middle 1/3 invasion and deep $1 / 3$ invasion can increase the risk of LVSI+ significantly, with a odds ratio (OR) of $3.494(p=0.000)$ and 15.203 $(p=0.000)$ separately.

Among 110 LVSI+ patients, 73 patients have received chemoradiotherapy after surgery, 31 patients received chemotherapy alone, 6 had no further treatment, and
Table 1 Demographic and clinical-pathological characteristic characteristics according to LVSI

\begin{tabular}{|c|c|c|c|}
\hline Characteristics & LVSI- & LVSI+ & $P$ value \\
\hline \multicolumn{4}{|l|}{ Age (years) } \\
\hline$<45$ & 112 & 41 & \multirow[t]{2}{*}{.166} \\
\hline$\geq 45$ & 135 & 69 & \\
\hline BMI & 23.15(2.94) & 23.97(3.32) & .030 \\
\hline \multicolumn{4}{|l|}{$\mathrm{SCC}(\mathrm{ng} / \mathrm{ml})$} \\
\hline$<1.5$ & 157 & 47 & \multirow[t]{2}{*}{.000} \\
\hline$\geq 1.5$ & 90 & 63 & \\
\hline \multicolumn{4}{|l|}{ Tumor size } \\
\hline$<2 \mathrm{~cm}$ & 177 & 60 & \multirow[t]{2}{*}{.002} \\
\hline$\geq 2 \mathrm{~cm}$ & 70 & 50 & \\
\hline \multicolumn{4}{|l|}{ FIGO stage } \\
\hline IB1 & 217 & 78 & \multirow[t]{2}{*}{.000} \\
\hline$\| \mathrm{A} 1$ & 30 & 32 & \\
\hline \multicolumn{4}{|l|}{ Surgical approach } \\
\hline Laparotomy & 24 & 8 & \multirow[t]{3}{*}{.508} \\
\hline Laparoscopic & 174 & 75 & \\
\hline Robotic & 49 & 27 & \\
\hline \multicolumn{4}{|c|}{ Histopathologic grades } \\
\hline G1 & 18 & 13 & \multirow[t]{3}{*}{.259} \\
\hline G2 & 216 & 89 & \\
\hline G3 & 13 & 8 & \\
\hline \multicolumn{4}{|c|}{ Lymph node involvement } \\
\hline Absent & 243 & 97 & \multirow[t]{2}{*}{.000} \\
\hline Present & 4 & 13 & \\
\hline \multicolumn{4}{|l|}{ Stromal invasion } \\
\hline Superficial 1/3 & 185 & 36 & \multirow[t]{3}{*}{.000} \\
\hline Middle $1 / 3$ & 56 & 48 & \\
\hline Deep 1/3 & 6 & 26 & \\
\hline
\end{tabular}

Values are presented as mean (standard deviation) or number

Chi-square test and t-test for $P$ values

SCC Squamous cell carcinoma antigen, G1 Well differentiated, G2 Moderately differentiated, G3 Poorly or undifferentiated

none received radiotherapy alone. Because of limited data size of other groups, only patients of chemoradiotherapy and chemotherapy were included into further analysis.

Demographic characteristics and clinicopathologic characteristics of LVSI+ patients received CT and CRT are showed in Table 3. Demographic characteristics such as age and BMI between chemotherapy group and chemoradiotherapy group were well balanced. All these patients have undergone a radical hysterectomy and pelvic lymphadenectomy with or without oophorosalpingectomy. None of these patients showed parametrial invasion or positive surgical margin. For included patients, FIGO Stage (2009), SCC value, surgical approach, tumor differentiation and lymph node 
Table 2 Multivariate analysis of clinical-pathological characteristics and lymphovascular space invasion

\begin{tabular}{|c|c|c|c|c|}
\hline & \multirow[t]{2}{*}{$P$ value } & \multirow[t]{2}{*}{ OR } & \multicolumn{2}{|c|}{$95 \% \mathrm{Cl}$ of OR } \\
\hline & & & Lower limit & Upper limit \\
\hline \multicolumn{5}{|l|}{ Age } \\
\hline$<45$ years & & Ref. & & \\
\hline$\geq 45$ years & .998 & 1.001 & .558 & 1.796 \\
\hline BMl & .328 & 1.048 & .954 & 1.151 \\
\hline \multicolumn{5}{|l|}{ Tumor size } \\
\hline$<2 \mathrm{~cm}$ & & Ref. & & \\
\hline$\geq 2 \mathrm{~cm}$ & .615 & 1.169 & .635 & 2.151 \\
\hline \multicolumn{5}{|l|}{ SCC } \\
\hline$<1.5$ & & Ref. & & \\
\hline$\geq 1.5$ & .346 & 1.335 & .732 & 2.434 \\
\hline \multicolumn{5}{|l|}{ Surgical approach } \\
\hline Laparotomy & .407 & Ref. & & \\
\hline Laparoscopic & .614 & 1.288 & .481 & 3.449 \\
\hline Robotic & .247 & 1.937 & .632 & 5.938 \\
\hline \multicolumn{5}{|l|}{ FIGO stage } \\
\hline IB1 & & Ref. & & \\
\hline$\| \mathrm{A} 1$ & .129 & 1.793 & .843 & 3.812 \\
\hline \multicolumn{5}{|c|}{ Depth of stromal invasion } \\
\hline Superficial 1/3 & .000 & Ref. & & \\
\hline Middle 1/3 & .000 & 3.494 & 1.900 & 6.426 \\
\hline Deep 1/3 & .000 & 15.203 & 4.668 & 49.516 \\
\hline \multicolumn{5}{|c|}{ Lymph node involvement } \\
\hline Absent & & Ref. & & \\
\hline Present & .085 & 3.443 & .843 & 14.070 \\
\hline \multicolumn{5}{|c|}{ Histopathologic grades } \\
\hline G1 & .669 & Ref. & & \\
\hline $\mathrm{G} 2$ & .418 & .669 & .253 & 1.769 \\
\hline G3 & .881 & .892 & .200 & 3.978 \\
\hline
\end{tabular}

Binary Logistic regression for $P$ values

OR Odds ratio, $C I$ Confidence interval, SCC Squamous cell carcinoma antigen, G1 Well differentiated, G2 Moderately differentiated, G3 Poorly or undifferentiated

metastasis were not significantly different. While deep stromal invasion presented a statistical significance $(P=0.001)$.

For all patients of chemotherapy group and chemoradiotherapy group, median follow-up time was 49.50 months (IQR 41.25-62.50) at the time of the analysis and $27.88 \%$ of patients had reached 5 years of follow-up. Up to the time of telephone interview, 9 patients were found relapsed (5 in chemotherapy group, 3 in chemoradiotherapy group and 1 in observation group). Among these patients, there were 2 pelvic recurrences, 2 pulmonary metastasis and 1 hepatic metastasis as well as skeletal metastasis in chemotherapy group; 2 multiple lymph node metastases
Table 3 Comparation of clinical-pathological characteristics of LVSI+ patients received CT and CRT

\begin{tabular}{|c|c|c|c|}
\hline Characteristics & Chemotherapy & Chemoradiotherapy & $P$ value \\
\hline \multicolumn{4}{|l|}{ Age (years) } \\
\hline$<45$ & 14 & 25 & \multirow[t]{2}{*}{.293} \\
\hline$\geq 45$ & 17 & 48 & \\
\hline BMI & $24.09(3.26)$ & 23.97(3.76) & .872 \\
\hline \multicolumn{4}{|l|}{ Tumor size } \\
\hline$<2 \mathrm{~cm}$ & 17 & 40 & \multirow[t]{2}{*}{.997} \\
\hline$\geq 2 \mathrm{~cm}$ & 14 & 33 & \\
\hline \multicolumn{4}{|l|}{ FIGO stage } \\
\hline $\mid \mathrm{B} 1$ & 21 & 48 & \multirow[t]{2}{*}{.844} \\
\hline$\| A 1$ & 10 & 25 & \\
\hline \multicolumn{4}{|l|}{$\mathrm{SCC}(\mathrm{ng} / \mathrm{ml})$} \\
\hline$<1.5$ & 12 & 30 & \multirow[t]{2}{*}{.821} \\
\hline$\geq 1.5$ & 19 & 43 & \\
\hline \multicolumn{4}{|c|}{ Surgical approach } \\
\hline Laparotomy & 3 & 4 & \multirow[t]{3}{*}{.391} \\
\hline Laparoscopic & 23 & 49 & \\
\hline Robotic & 5 & 20 & \\
\hline \multicolumn{4}{|c|}{ Histopathologic grades } \\
\hline G1 & 6 & 7 & \multirow[t]{3}{*}{.346} \\
\hline G2 & 21 & 58 & \\
\hline G3 & 4 & 8 & \\
\hline \multicolumn{4}{|c|}{ Lymph node involvement } \\
\hline Absent & 29 & 60 & \multirow[t]{2}{*}{.221} \\
\hline Present & 2 & 13 & \\
\hline \multicolumn{4}{|l|}{ Stromal invasion } \\
\hline Inner 1/3 & 18 & 15 & \multirow[t]{3}{*}{.001} \\
\hline Middle 1/3 & 9 & 35 & \\
\hline Outer $1 / 3$ & 4 & 23 & \\
\hline
\end{tabular}

Values are presented as mean (standard deviation) or number

Chi-square test and t-test for $P$ values. Among $110 \mathrm{LVSI}+$ patients, 73 patients have received chemoradiotherapy, 31 received chemotherapy, 6 had no further treatment, and none received radiotherapy alone. Because of limited data size of other groups, only patients of chemoradiotherapy and chemotherapy were included

SCC Squamous cell carcinoma antigen, G1 Well differentiated, G2 Moderately differentiated, G3 Poorly or undifferentiated

throughout the body and 1 relapse in anal area in chemoradiotherapy group; 1 pelvic recurrence in observation group.

In univariate analysis of different characteristics and progression-free survival, the present study revealed that tumor differentiation $(P=0.001)$ and postoperative therapy $(P=0.036)$ had a significant influence on disease recurrence (Table 4). Between different postoperative therapies, CT group presented 5 relapses, with a mean PFS of 71.020 month, whereas 3 recurrences were presented at CRT group, with a mean PFS of 80.027 month $(P=0.036)$ (Fig. 1A). Other clinical- and 
Table 4 Univariate analysis of different characteristics and progression-free survival of LVSI+ population

\begin{tabular}{|c|c|c|c|c|c|}
\hline & \multirow[t]{2}{*}{ Mean PFS } & \multirow[t]{2}{*}{ SE } & \multicolumn{2}{|c|}{$95 \% \mathrm{Cl}$ of $\mathrm{PFS}$} & \multirow[t]{2}{*}{$\mathbf{P}$} \\
\hline & & & Lower limit & Upper limit & \\
\hline \multicolumn{6}{|l|}{ Age } \\
\hline$<45$ years & 77.564 & 3.025 & 71.635 & 83.493 & \multirow[t]{2}{*}{.997} \\
\hline$\geq 45$ years & 72.486 & 1.966 & 68.633 & 76.339 & \\
\hline \multicolumn{6}{|l|}{ Tumor size } \\
\hline$<2 \mathrm{~cm}$ & 76.985 & 2.594 & 71.901 & 82.068 & \multirow[t]{2}{*}{.656} \\
\hline$\geq 2 \mathrm{~cm}$ & 72.368 & 2.048 & 68.354 & 76.381 & \\
\hline \multicolumn{6}{|l|}{$\operatorname{sCC}(\mathrm{ng} / \mathrm{ml})$} \\
\hline$<1.5$ & 75.167 & 1.985 & 71.276 & 79.059 & \multirow[t]{2}{*}{.377} \\
\hline$\geq 1.5$ & 76.451 & 2.560 & 71.434 & 81.468 & \\
\hline \multicolumn{6}{|l|}{ Surgical approach } \\
\hline Laparotomy & - & - & - & - & - \\
\hline Laparoscopic & 78.345 & 2.422 & 73.597 & 83.092 & \multirow[t]{2}{*}{.418} \\
\hline Robotic & 65.120 & 1.842 & 61.510 & 68.730 & \\
\hline \multicolumn{6}{|l|}{ FIGO stage } \\
\hline $\mid \mathrm{B} 1$ & 80.089 & 1.665 & 76.825 & 83.353 & \multirow[t]{2}{*}{.072} \\
\hline$\| \mathrm{A} 1$ & 71.688 & 3.877 & 64.090 & 79.287 & \\
\hline \multicolumn{6}{|c|}{ Depth of stromal invasion } \\
\hline Superficial 1/3 & 66.870 & 3.821 & 59.381 & 74.359 & \multirow[t]{3}{*}{.153} \\
\hline Middle $1 / 3$ & 80.152 & 1.985 & 76.262 & 84.042 & \\
\hline Deep 1/3 & 69.778 & 2.181 & 65.504 & 74.052 & \\
\hline \multicolumn{6}{|c|}{ Lymph node invasion } \\
\hline Absent & 79.135 & 1.691 & 75.820 & 82.450 & \multirow[t]{2}{*}{.061} \\
\hline Present & 62.028 & 5.345 & 51.551 & 72.505 & \\
\hline \multicolumn{6}{|c|}{ Histopathologic grades } \\
\hline G1 & 77.000 & 3.795 & 69.562 & 84.438 & \multirow[t]{3}{*}{.001} \\
\hline G2 & 80.354 & 1.502 & 77.410 & 83.299 & \\
\hline G3 & 49.667 & 7.237 & 35.481 & 63.852 & \\
\hline \multicolumn{6}{|l|}{ Adjuvant therapy } \\
\hline Chemotherapy & 71.020 & 4.136 & 62.913 & 79.127 & \multirow[t]{2}{*}{.036} \\
\hline $\begin{array}{l}\text { Chemoradio- } \\
\text { therapy }\end{array}$ & 80.027 & 1.681 & 76.732 & 83.323 & \\
\hline
\end{tabular}

Log-rank test for $p$-values

SE Standard error, CI Confidence interval, SCC Squamous cell carcinoma antigen, G1 Well differentiated, G2 Moderately differentiated, G3 Poorly or undifferentiated

pathological factors such as age, tumor size, SCC value, FIGO stage, DSI and lymph node invasion didn't influent PFS significantly. As for surgical approach, we only conducted a comparison between laparoscopic surgery and robot-assisted surgery because of no recurrence in laparotomy group, and no significant difference were found. In multivariate analysis, Cox proportional hazard model showed that lymph node metastasis $(P=0.017)$, tumor differentiation $(P=0.036)$ and postoperative therapy $(P=0.021)$ can increase the risk of tumor relapse (Table 5).
Meanwhile, 3 deaths were identified in the present study, 2 in chemotherapy group and 1 in observation group. The 2 deaths of chemotherapy group occurred at 12th month after hepatic and skeletal metastasis and 59th month after pelvic recurrence separately. While up to the time of data analysis, all patients received chemoradiotherapy were alive. As a result of data limitation, we only reached to compared the overall survival between different adjuvant treatment regimens, and have found a statistical significance between $\mathrm{CT}$ and CRT group $(P=0.021)$ (Fig. 1B).

\section{Discussion}

The current study revealed that deep stromal invasion was the single independent risk factor of LVSI+. In survival analysis, univariate analysis indicated that poorer tumor differentiation and postoperative chemotherapy alone are associated with higher possibility of recurrence for LVSI+ early-stage invasive squamous cervical carcinoma. Cox proportional hazard model indicated that the presence of lymph node metastasis, poorly or undifferentiated tumor and postoperative chemotherapy alone are associated with higher recurrence rate.

The present study found that DSI can significantly increase the incidence of LVSI+ in cervical cancer, which is consistent with previous evidences $[19,20]$. Criteria of DSI varies from different studies, the current study divided depth of stromal invasion as superficial $1 / 3$, middle $1 / 3$, and deep $1 / 3$, which is in accordance with the Sedlis criteria. Moreover, the present study showed that both middle $1 / 3$ invasion and deep 1/3 invasion can significantly increase the incidence of LVSI+, validating the relationship between DSI and LVSI in spite of different definition of DSI. While the present study revealed that DSI is the only independent risk factor of LVSI+, more reports showed that lymph node metastasis is closely associated with LVSI+ [19-21]. Our study also found significant relationship between lymph node metastasis and LVSI+ in univariate analysis. In addition, since the publication of Laparoscopic Approach to Cervical Cancer (LACC) trial in 2018 [22], there have been controversy on optimal surgical approach of early-stage cervical cancer. It is believed that the utilization of manipulator allows malignant cells to spread into vascular and lymphatic vessels by squeezing tumor lesion, thus result in tumor relapse of pelvic cavity. Nevertheless, in the current study, different surgical approach didn't influence the incidence of LVSI significantly. A recent prospective study also found that surgical approach and the utilization of manipulator are not associated with LVSI in cervical cancer [23].

To our knowledge, the present study is the first study focusing on postoperative treatment regimen of LVSI+ 

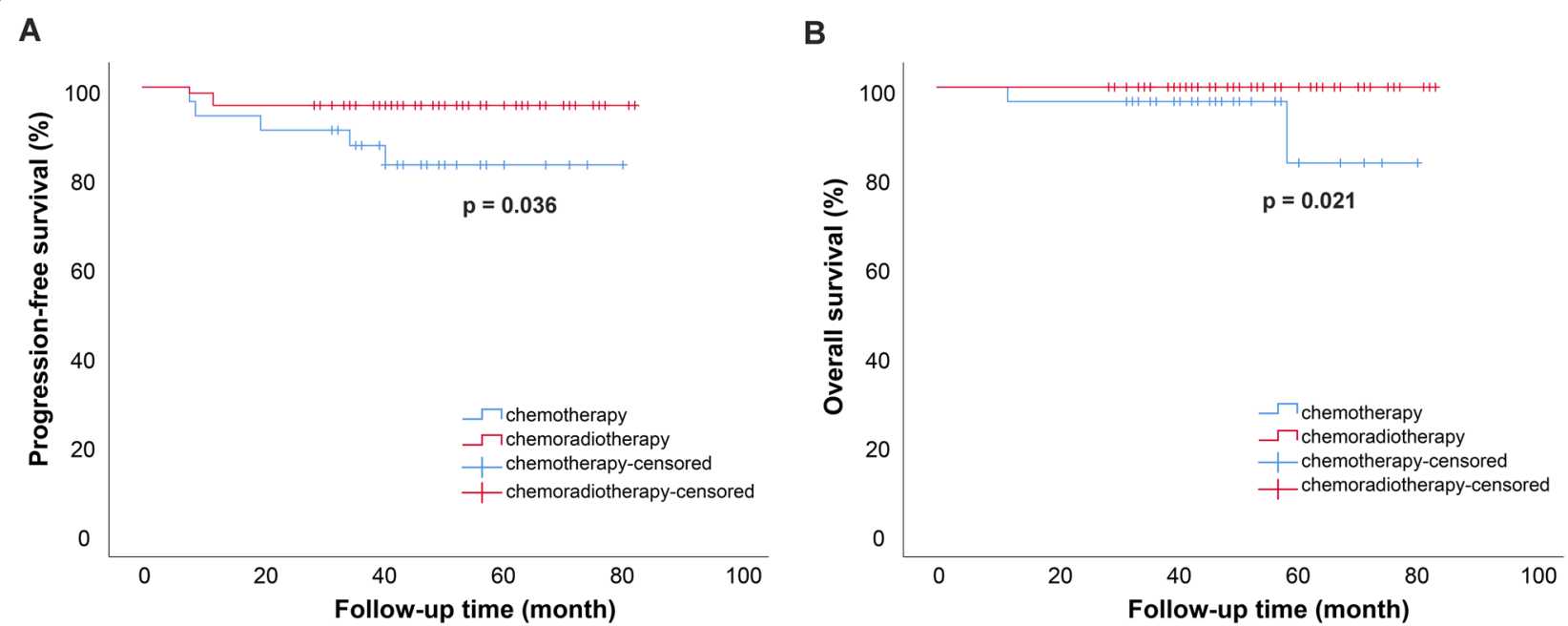

Fig. 1 Survival curves based on postoperative therapy on LVSI+ patients $(n=104)$. Log-rank test for $p$-values. Survival curves are shown for $\mathbf{A}$ PFS and $\mathbf{B}$ OS. PFS, progression free survival; OS, overall survival

Table 5 Multivariate analysis of different characteristics and progression-free survival of LVSI+ population

\begin{tabular}{|c|c|c|c|c|}
\hline \multirow[t]{2}{*}{ Characteristics } & \multirow[t]{2}{*}{$P$ value } & \multirow[t]{2}{*}{ HR } & \multicolumn{2}{|l|}{$95 \% \mathrm{Cl}$ of $\mathrm{HR}$} \\
\hline & & & Lower limit & Upper limit \\
\hline \multicolumn{5}{|l|}{ Tumor size } \\
\hline$<2 \mathrm{~cm}$ & & Ref. & & \\
\hline$\geq 2 \mathrm{~cm}$ & .076 & .065 & .003 & 1.327 \\
\hline \multicolumn{5}{|l|}{ Surgical approach } \\
\hline Laparotomy & .706 & Ref. & & \\
\hline Laparoscopic & .992 & .000 & .000 & .000 \\
\hline Robotic & .404 & 3.750 & .168 & 83.764 \\
\hline \multicolumn{5}{|l|}{ FIGO stage } \\
\hline IB1 & & Ref. & & \\
\hline$\| \mathrm{A} 1$ & .123 & 8.073 & .567 & 115.040 \\
\hline \multicolumn{5}{|l|}{ Depth of stromal invasion } \\
\hline Superficial 1/3 & 699 & Ref. & & \\
\hline Middle $1 / 3$ & .642 & .628 & .089 & 4.446 \\
\hline Deep 1/3 & .588 & 2.283 & .115 & 45.388 \\
\hline \multicolumn{5}{|c|}{ Lymph node metastasis } \\
\hline Absent & & Ref. & & \\
\hline Present & .017 & 96.283 & 2.247 & 4125.335 \\
\hline \multicolumn{5}{|l|}{ Adjuvant therapy } \\
\hline Chemotherapy & & Ref. & & \\
\hline Chemoradiotherapy & .021 & .042 & .003 & .621 \\
\hline \multicolumn{5}{|l|}{ Histopathologic grades } \\
\hline G1 & .022 & Ref. & & \\
\hline G2 & .540 & 2.722 & .110 & 67.169 \\
\hline G3 & .036 & 83.727 & 1.333 & 5260.175 \\
\hline
\end{tabular}

A Cox proportional hazard regression model for $p$-values

SE Standard error, HR Hazard ratio, Cl Confidence interval, SCC Squamous cell carcinoma antigen, G1 Well differentiated, G2 Moderately differentiated, G3 Poorly or undifferentiated early-stage invasive squamous cervical carcinoma as well as the first study comparing postoperative chemotherapy alone and chemoradiotherapy in intermediate risk individuals of cervical cancer. In the current study, both univariate analysis and Cox proportional hazard model indicated that compared to postoperative CT alone, CRT is associated with prolonged PFS of cervical cancer. Being one of intermediate risk factors of poor prognosis, it is still controversial whether LVSI is an independent risk factor of higher recurrence rate and mortality. Nevertheless, when it is combined with other intermediate risk factors such as DSI and large tumor size, the recurrence rate increases up to 15-20\% [17]. Cancer cells spread into vascular and lymphatic vessels might contribute to tumor involvement [19]. Therefore, LVSI might play a crucial role in metastasis. Based on its natural feature of involving inside vascular and lymphatic vessels, it is reasonable to consume that adjuvant systemic treatment contributes to inhibit cancer cell spread. Furthermore, as a result to limited access to effective radiotherapy, radiotherapy is not available for patients in many developing countries $[3,24]$. At present, there are only limited data on the role of chemotherapy in postoperative treatment. A retrospective study comparing CT and RT in FIGO stage IB1 and IIA1 cervical carcinoma indicates that RT group had a significantly longer PFS, while difference in OS was not significant [24]. In a nation-wide study analyzed the prognosis of 555 intermediate-risk individuals with stage IB cervical cancer after different adjuvant therapies (chemotherapy, radiotherapy and chemoradiotherapy), and have found that patients who received postoperative chemotherapy alone presented similar PFS and OS with other two groups, suggesting the effectiveness of chemotherapy 
as adjuvant therapy in intermediate-risk cervical cancer [25]. However, existed studies are mostly retrospective analysis, to have a better understanding of optimal adjuvant treatment in LVSI+ early invasive cervical cancer, large-scale prospective trial is still warranted.

Survival analysis in the present study suggested that poorly or undifferentiated tumor is associated with higher risk of recurrence for cervical cancer. This is consistent with previous reports. A retrospective observational study analyzing 31,536 women with squamous cervical cancer revealed that compared to well-differentiated tumors, both moderately-differentiated tumors and poorly or undifferentiated tumors were independently related to decreased cause-specific survival. Furthermore, poorly or undifferentiated tumor s were associated with significantly decreased cause-specific survival compared to grade moderately-differentiated [26]. However, this report didn't describe data on tumor recurrence. There have been studies on the mechanism for the relationship between tumor differentiation and prognosis in squamous cervical cancer. According to prior studies, poorly or undifferentiated tumors are associated with lower keratin, which is usually more aggressive with epithelial-mesenchymal transition (EMT) [27]. Epithelial cancer cells obtain migration and invasion ability in the bloodstream after EMT [28], leading to cancer cells spread and inferior prognosis. It is speculated that poorly or undifferentiated tumor alters prognosis through lower keratin [26]. Nevertheless, further investigation is still required to validate this theory.

The present study is a retrospective study, there might be confounding variables that were not taken into account. For example, baseline characteristic comparation of chemotherapy and chemoradiotherapy group indicated a statistical significance on depth of stromal invasion. In consideration of potential worse prognosis in women with DSI, chemoradiotherapy are more likely to be administered to this group of patients, thus weaken the impact of DSI on DFS and OS. A limitation of the study is that data size was limited. As a result, patients who received radiotherapy and only followup was not included in data analysis, which prevented us from organizing a comprehensive study of different adjuvant therapy on FIGO stages IB1 and IIA1 cervical squamous cancer patients with LVSI. However, in the real-world setting, some patients with intermediate pathologic risk factors are receiving postoperative radiotherapy alone or observation. In addition, no death was found in CRT group, hence sub-group analysis and multivariable analysis of OS were not available. Although considering the synergistic effects of chemotherapy and radiotherapy, it was reasonable to consume that OS of patients who received chemoradiation would be better than those who received chemotherapy in LVSI positive patients, clinical evidences are still required to confirm it. Therefore, large-scale studies are warranted in order to obtain a better understanding of adjuvant therapy on cervical cancer patients with intermediate risk. A weakness of this study is that toxicity and side effects of the regimens were not accounted for in this study, which might affect compliance and tolerance of patients. In addition to disease control, for patients with malignancy, quality of life also worth to discuss.

In spite of these limitations, this is the first study of postoperative treatment for LVSI+ early-stage invasive squamous cervical carcinoma. It is also the first study comparing postoperative chemotherapy alone and chemoradiotherapy in intermediate risk individuals of cervical cancer. Compared with existed studies, the follow-up time of the present study is relatively long. The current study revealed that DSI was significantly associated to LVSI+ for FIGO stages IB1 and IIA1 cervical squamous cancer patients. Compared with chemotherapy, chemoradiotherapy seems to improve progression-free survival in squamous cervical cancer patients with lymphovascular space invasion.

\begin{abstract}
Abbreviations
Cl: Confidence interval; CRT: Chemoradiotherapy; CT: Chemotherapy alone; DSI: Deep stromal invasion; EMT: Epithelial-mesenchymal transition; G1: Well differentiated; G2: Moderately differentiated; G3: Poorly or undifferentiated; HR: Hazard ratio; LVSI: Lymphovascular space invasion; OR: Odds ratio; OS: Overall survival; PFS: Progression-free survival; RT: Radiotherapy alone; SCC: Squamous cell carcinoma antigen; SE: Standard error.
\end{abstract}

\section{Acknowledgements}

Not applicable.

Code availability

Not applicable.

\section{Authors' contributions}

All authors contributed to the study conception and design. $\mathrm{HZ}$ participated data collection and analyze, wrote the original draft and revised the final version. RY was involved in data collection and analyze, she also contributed in manuscript revision. LZ and RW helped with data curation and patient Investigation. LX was involved in the conception and design of the study, revised the manuscript and supervised the whole study. All authors have read and approved the manuscript.

Funding

There's no funding relevant to this article.

Availability of data and materials

The datasets used and analysed during the current study are available from the corresponding author on reasonable request.

\section{Declarations}

Ethics approval and consent to participate

The study protocol was established, according to the ethical guidelines of the Helsinki Declaration and was approved by the Human Ethics Committee of 
The First Affiliated Hospital of Chongqing Medical University. Medical records were obtained with informed consent of all patients.

\section{Consent for publication}

Not applicable.

\section{Competing interests}

No potential conflict of interest relevant to this article was reported.

Received: 14 June 2021 Accepted: 17 February 2022

Published online: 23 February 2022

\section{References}

1. Sung H, Ferlay J, Siegel RL, Laversanne M, Soerjomataram I, Jemal A, et al. Global cancer statistics 2020: GLOBOCAN estimates of incidence and mortality worldwide for 36 cancers in 185 countries. CA Cancer J Clin. 2021;71(3):209-49.

2. Bhatla N, Aoki D, Sharma DN, Sankaranarayanan R. Cancer of the cervix uteri. Int J Gynaecol Obstet. 2018;143(Suppl 2):22-36.

3. Barton MB, Frommer M, Shafiq J. Role of radiotherapy in cancer control in low-income and middle-income countries. Lancet Oncol. 2006:7(7):584-95.

4. dos Reis R, Burzawa JK, Tsunoda AT, Hosaka M, Frumovitz M, Westin SN, et al. Lymphovascular space invasion portends poor prognosis in low-risk endometrial cancer. Int J Gynecol Cancer. 2015;25(7):1292-9.

5. Ayhan A, Sahin H, Sari ME, Yalcin I, Haberal A, Meydanli MM. Prognostic significance of lymphovascular space invasion in low-risk endometrial cancer. Int J Gynecol Cancer. 2019;29(3):505-12.

6. Hahn HS, Lee IH, Kim TJ, Lee KH, Shim JU, Kim JW, et al. Lymphovascular space invasion is highly associated with lymph node metastasis and recurrence in endometrial cancer. Aust N Z J Obstet Gynaecol. 2013;53(3):293-7.

7. Hanson MB, van Nagell JR Jr, Powell DE, Donaldson ES, Gallion H, Merhige $M$, et al. The prognostic significance of lymph-vascular space invasion in stage I endometrial cancer. Cancer. 1985;55(8):1753-7.

8. Matsuo K, Garcia-Sayre J, Medeiros F, Casabar JK, Machida H, Moeini A, et al. Impact of depth and extent of lymphovascular space invasion on lymph node metastasis and recurrence patterns in endometrial cancer. J Surg Oncol. 2015;112(6):669-76.

9. Pavlakis K, Rodolakis A, Vagios S, Voulgaris Z, Messini I, Yiannou P, et al. Identifiable risk factors for lymph node metastases in grade 1 endometrial carcinoma. Int J Gynecol Cancer. 2017;27(8):1694-700.

10. Veade AE, Foote J, Ehrisman J, Broadwater G, Davidson BA, Lee PS, et al. Associations between lymphovascular space invasion, nodal recurrence, and survival in patients with surgical stage I endometrioid endometrial adenocarcinoma. World J Surg Oncol. 2019;17(1):80.

11. Rotman M, Sedlis A, Piedmonte MR, Bundy B, Lentz SS, Muderspach LI, et al. A phase III randomized trial of postoperative pelvic irradiation in stage IB cervical carcinoma with poor prognostic features: follow-up of a gynecologic oncology group study. Int J Radiat Oncol Biol Phys. 2006:65(1):169-76.

12. Sedlis A, Bundy BN, Rotman MZ, Lentz SS, Muderspach LI, Zaino RJ. A randomized trial of pelvic radiation therapy versus no further therapy in selected patients with stage IB carcinoma of the cervix after radical hysterectomy and pelvic lymphadenectomy: a gynecologic oncology group study. Gynecol Oncol. 1999;73(2):177-83.

13. Ho CM, Chien TY, Huang SH, Wu CJ, Shih BY, Chang SC. Multivariate analysis of the prognostic factors and outcomes in early cervical cancer patients undergoing radical hysterectomy. Gynecol Oncol. 2004:93(2):458-64.

14. Rosa DD, Medeiros LR, Edelweiss MI, Pohlmann PR, Stein AT. Adjuvant platinum-based chemotherapy for early stage cervical cancer. Cochrane Database Syst Rev. 2012;13;6(6):CD005342.

15. Kim K, Kang SB, Chung HH, Kim JW, Park NH, Song YS. Comparison of chemoradiation with radiation as postoperative adjuvant therapy in cervical cancer patients with intermediate-risk factors. Eur J Surg Oncol. 2009;35(2):192-6.
16. Ryu SY, Park SI, Nam BH, Cho CK, Kim K, Kim BJ, et al. Is adjuvant chemoradiotherapy overtreatment in cervical cancer patients with intermediate risk factors? Int J Radiat Oncol Biol Phys. 2011;79(3):794-9.

17. Takekuma M, Kasamatsu Y, Kado N, Kuji S, Tanaka A, Takahashi N, et al. The issues regarding postoperative adjuvant therapy and prognostic risk factors for patients with stage I-II cervical cancer: a review. J Obstet Gynaecol Res. 2017:43(4):617-26.

18. Kim H, Park W, Kim YS, Kim YJ. Chemoradiotherapy is not superior to radiotherapy alone after radical surgery for cervical cancer patients with intermediate-risk factor. J Gynecol Oncol. 2020;31(3):e35.

19. Yan W, Qiu S, Ding Y, Zhang Q, Si L, Lv S, et al. Prognostic value of lymphovascular space invasion in patients with early stage cervical cancer in Jilin China: a retrospective study. Medicine (Baltimore). 2019;98(40):e17301.

20. Zhu J, Cao L, Wen H, Bi R, Wu X, Ke G. The clinical and prognostic implication of deep stromal invasion in cervical cancer patients undergoing radical hysterectomy. J Cancer. 2020;11(24):7368-77.

21. Milam MR, Frumovitz M, dos Reis R, Broaddus RR, Bassett RL Jr, Ramirez PT. Preoperative lymph-vascular space invasion is associated with nodal metastases in women with early-stage cervical cancer. Gynecol Oncol. 2007;106(1):12-5.

22. Ramirez PT, Frumovitz M, Pareja R, Lopez A, Vieira M, Ribeiro R, et al. Minimally invasive versus abdominal radical hysterectomy for cervical cancer. N Engl J Med. 2018;379(20):1895-904.

23. Liu $Y$, Huang $S$, Ming $X$, Jing $H$, Li Z . Surgical approach and use of uterine manipulator are not associated with LVSI in surgery for early-stage cervical cancer. J Minim Invasive Gynecol. 2021;28(9):1573-8.

24. Li L, Song X, Liu R, Li N, Zhang Y, Cheng Y, et al. Chemotherapy versus radiotherapy for FIGO stages IB1 and IIA1 cervical carcinoma patients with postoperative isolated deep stromal invasion: a retrospective study. BMC Cancer. 2016;16:403.

25. Matsuo K, Shimada M, Yokota H, Satoh T, Katabuchi H, Kodama S, et al. Effectiveness of adjuvant systemic chemotherapy for intermediate-risk stage IB cervical cancer. Oncotarget. 2017;8(63):106866-75.

26. Matsuo K, Mandelbaum RS, Machida H, Purushotham S, Grubbs BH, Roman LD, et al. Association of tumor differentiation grade and survival of women with squamous cell carcinoma of the uterine cervix. J Gynecol Oncol. 2018;29(6):e91

27. Cancer Genome Atlas Research N, Albert Einstein College of M, Analytical Biological S, Barretos Cancer H, Baylor College of M, Beckman Research Institute of City of $\mathrm{H}$, et al. Integrated genomic and molecular characterization of cervical cancer. Nature. 2017;543(7645):378-84.

28. Azevedo AS, Follain G, Patthabhiraman S, Harlepp S, Goetz JG. Metastasis of circulating tumor cells: favorable soil or suitable biomechanics, or both? Cell Adhes Migr. 2015;9(5):345-56

\section{Publisher's Note}

Springer Nature remains neutral with regard to jurisdictional claims in published maps and institutional affiliations.

Ready to submit your research? Choose BMC and benefit from

- fast, convenient online submission

- thorough peer review by experienced researchers in your field

- rapid publication on acceptance

- support for research data, including large and complex data types

- gold Open Access which fosters wider collaboration and increased citations

- maximum visibility for your research: over 100M website views per year

At BMC, research is always in progress.

Learn more biomedcentral.com/submissions 